\title{
Botulinum Toxin Injection for Treatment of Chronic Anal Fissure: Is There Any Dose-Dependent Efficiency? A Meta- Analysis
}

\author{
Adam Bobkiewicz ${ }^{1}$ Wojciech Francuzik ${ }^{2}$ - Lukasz Krokowicz ${ }^{1}$ - Adam Studniarek ${ }^{1}$ • \\ Witold Ledwosiński ${ }^{1} \cdot$ Jacek Paszkowski $^{1} \cdot$ Michal Drews $^{1} \cdot$ Tomasz Banasiewicz $^{1}$
}

Published online: 18 August 2016

(c) The Author(s) 2016. This article is published with open access at Springerlink.com

\begin{abstract}
Background Chronic anal fissure (CAF) is a linear split of the anoderm. The minimally invasive management of CAF such as botulinum toxin (BT) injection is recommended. However, the exact efficient dose of BT, number of injections per session and the injection sites are still debatable. The aim of this analysis was to assess the dosedependent efficiency of botulinum toxin injection for CAF.

Methods PubMed and Web of Science databases were searched for terms: "anal fissure" AND "botulinum toxin." Studies published between October 1993 and May 2015 were included and had to meet the following criteria: (1) chronic anal fissure, (2) prospective character of the study, (3) used simple BT injection without any other interventions and (4) no previous treatment with BT.

Results A total of 1577 patients from 34 prospective studies used either Botox or Dysport formulations were qualified for this meta-analysis. A total number of BT units per session ranged from 5 to $150 \mathrm{IU}$, whereas the efficiency across analyzed studies ranged from 33 to $96 \%$. Surprisingly, we did not observe a dose-dependent efficiency (Spearman's rank correlation coefficient, $\rho=0.060 ; p=0.0708$ ). Moreover, there were no BT dosedependent postoperative complications or fecal incontinence and significant difference in healing rates compared BT injection into the anal sphincter muscles.

Conclusions BT injection has been an accepted method for the management of CAF. Surprisingly, there is no dosedependent efficiency, and the postoperative incontinence rate is not related to the BT dosage regardless the type of formulation of botulinum neurotoxin used. Moreover, no difference in healing rate has been observed in regard to the site and number of injections per session.
\end{abstract}

The original version of this article was revised: In the initial online publication, the authors' family names and given names were interchanged.

Adam Bobkiewicz

bobofon007@gmail.com

1 Department of General, Endocrinological Surgery and Gastroenterological Oncology, Poznan University of Medical Sciences, Przybyszewskiego 49, 60-355 Poznan, Poland

2 Department of Dermatology, Venerology and Allergology, Charité - Universitätsmedizin Berlin, Charitéplatz 1, 10117 Berlin, Germany

\section{Introduction}

An anal fissure is defined as a tear in the skin within the distal anal canal. A chronic anal fissure (CAF) usually occurs in young adults and affects both sexes equally and is predominantly localized at the posterior commissure of the anal canal which is possibly associated with local hypoperfusion at the posterior midline [1,2]. Although the exact pathogenesis of anal fissure is still unclear, based on recent studies, a local ischemia seems to play a crucial role in the pathogenesis. The increased resting anal tone of internal sphincter muscle influences prolonged compression of 
anodermal arteries passing through the muscle, resulting in local ischemia [3, 4].

Lateral internal sphincterotomy primary described by Eisenhammer has been widely accepted as a gold standard surgical procedure for chronic anal fissure. However, the potential risk of postoperative complications including gas or stool incontinence is caused by the fact that recently there has been more focus on less invasive management such as chemical sphincterotomy of CAF [5, 6]. The use of varying topical pharmacological agents such as isosorbide dinitrate, glyceryl trinitrate, calcium antagonists or muscarinic agonists has been used with varying healing rates [7-9]. However, the fundamental drawbacks of these therapies are short-term effectiveness and potential side effects $[10,11]$. Recently, botulinum toxin (BT) has been adopted for the treatment of chronic anal fissure. An injection of BT leads to the blockade of acetylcholine release and causes short-term paralysis of internal sphincter muscle, resulting in a reduction in anal tone $[12,13]$.

Although this method of treatment has been used worldwide, a firm recommendation for the injection of BT is still under debate. Moreover, there are no broadly established intervals between further injections and how many injections should be made at one session. There is limited information about how the dose of BT influences the potential postoperative gas or stool incontinence.

The main goal of the study was to answer crucial questions: (1) Is there any dose-dependent efficiency of BT for CAF, (2) Is there any correlation between doses of BT and potential complication rate including incontinence, (3) Is there any correlation between the site of injection (internal or external anal sphincter muscle) or the number of injections and the efficiency of BT injection for CAF.

\section{Materials and methods}

\section{Data sources and search strategy}

The study was performed at tertiary reference teaching hospital. A comprehensive literature search was performed independently by four investigators. PubMed and Web of Science database were searched for terms: "anal fissure" AND "botulinum toxin." Only English references published before May 2015 were included into the metaanalysis.

\section{Inclusion and exclusion criteria}

All studies included into the meta-analysis met the following criteria: (1) diagnosis of chronic anal fissure, (2) prospective character of the study, (3) simple botulinum toxin injection without any other interventions (e.g., simultaneous ointment application, lateral internal sphincterotomy and others) and (4) no previous treatment with botulinum toxin.

Studies comparing different doses of BT injection in different groups of patients were included into the study and listed separately for analysis. Either Botox or Dysport formulation of botulinum neurotoxin was included into the meta-analysis.

Studies such as: review, meta-analysis, letters to the editor, articles not in English, studies on animal models, case reports ( $n<10$ patients), conference abstracts, acute anal fissure, studies on pediatric population were excluded from the meta-analysis.

\section{Data inclusion}

The following data were collected from each study and included: author, year of publication, number of patients, type of BT formulation, site of BT injection (internal or external anal sphincter), dose of BT injected (total number of injected BT units), injection volume (total in $\mathrm{ml}$ per session), number of injections per session, efficiency (\%), length of follow-up (weeks), the type of follow-up (physical examination, questionnaire, manometry or others), complications (number and character) and rate of incontinence and time of resolving (weeks).

\section{Statistical analysis}

Efficacy was described as a treatment success rate, being the number of healed patients (without clinical symptoms) divided by the number of all treated patients (without the placebo control groups), expressed in percent. All calculations regarding dose dependencies were performed using Spearman's rank correlation test. $p$ values $<0.05$ were considered significant. Statistical analysis was performed with the use of $\mathrm{R}$ statistical package.

In the purpose of appropriate outcomes interpretation, conversion factor of $1: 3$ for Botox equivalent unit to Dysport formulation was used.

\section{Results}

A total of 286 studies were retrieved based on the publication search. A total of 26 citations were excluded because of duplication. A total of 198 publications were excluded from analysis because they did not meet the inclusion criteria. Finally, 34 studies were enrolled into the study meeting the criteria for meta-analysis. A total of 30 studies used Botox formulation, whereas in four studies Dysport formulation was used. The number of studies 


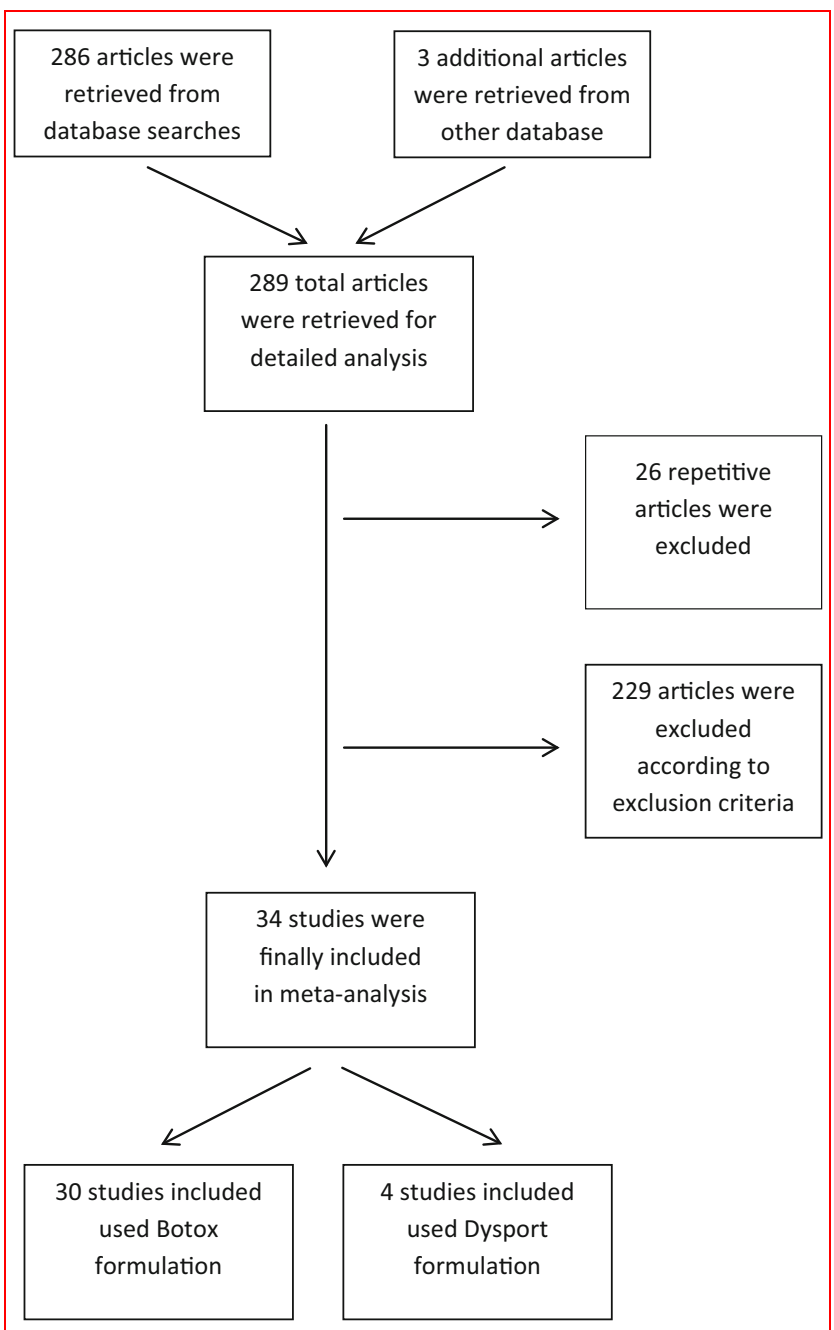

Fig. 1 Flowchart of the study

searched, evaluated and included into the meta-analysis is shown in the flowchart (Fig. 1).

A total of 1577 patients from 34 prospective studies were qualified for meta-analysis. Studies included in the meta-analysis are summarized in Table 1.

In majority of studies $(n=31,91.2 \%)$, preferably internal anal sphincter was injected. In all studies used Dysport formulation, only internal anal sphincter was injected, whereas in three studies with Botox formulation authors injected external anal sphincter. Usually, only two site of anal sphincter was preferred to be injected per session, whereas in two studies (Botox formulation), three sites of anal sphincter were injected with BT.

The results of BT treatment were evaluated based on physical examination (including per rectum examination) in 33 studies, questionnaire (usually self-evaluation of pain, bleeding and incontinence) in 10 studies and anorectal manometry in 19 studies. In one study, there was no explanation of methods.
The mean time of follow-up ranged from 4 to 156 weeks after BT injection. The mean time of follow-up was significantly shorter when compare Botox versus Dysport formulation of botulinum neurotoxin used $(28.9 \pm 42.6$ vs $10.2 \pm 2.1$ weeks).

A total of BT units per session ranged from 5 to $80 \mathrm{IU}$ and 10-150 in Botox and Dysport formulation groups, respectively. The efficiency across analyzed studies varied from 33 to $96 \%$ and from 67 to $94 \%$, respectively, for Botox and Dysport groups. The meta-analytical correlation between the amounts of BT units injected (analyzed separately for Botox and Dysport group) and its efficiency is illustrated in Fig. 2. Based on Spearman's rank correlation, there was no significant statistical correlation. Moreover, there was no significant statistical correlation when we used conversion factor of 1:3 for Botox equivalent unit to Dysport formulation (Fig. 3).

A total mean volume of injected BT (both Botox and Dysport) ranged from 0.2 to $1.0 \mathrm{ml}$ per session. There was no statistical correlation between total volume of BT injected and efficiency based on Spearman's rank correlation (Fig. 4).

A total of $35(2.22 \%)$ patients developed local postoperative complications such as hematoma, perianal thrombosis or perianal abscess as the most common ones. In fourteen studies, authors reported local complications, which ranged from one to eight per study. When we analyzed the amount of BT injections and the number of complications, we did not find any statistical correlation (Fig. 5). There was also no significant difference in postoperative complication rate between Botox and Dysport groups.

Seventy-nine $(5.01 \%)$ patients reported transient fecal incontinence, 51 patients in Botox group and 28 in Dysport group. However, in all cases symptoms resolved within a couple of weeks (ranged from 1 to 8 weeks). Surprisingly, we did not find any statistical correlation between amount of BT injection (units) and frequency of incontinence (Fig. 6). Moreover, there was no significant correlation between BT units and the time required for the resolution of incontinence caused by BT injection. There was also no significant difference when compare Botox and Dysport groups regarding incontinence rate.

In three studies with a total of 133 patients, BT was injected within the external anal sphincter, whereas in remaining thirty-one studies internal anal sphincter was preferably injected with BT. There was no significant difference in efficiency concerning the site of injection.

\section{Discussion}

A botulinum toxin (BT) injection has been widely accepted as the method of CAF treatment. High efficiency of BT injection for $\mathrm{CAF}$ was confirmed in many studies 


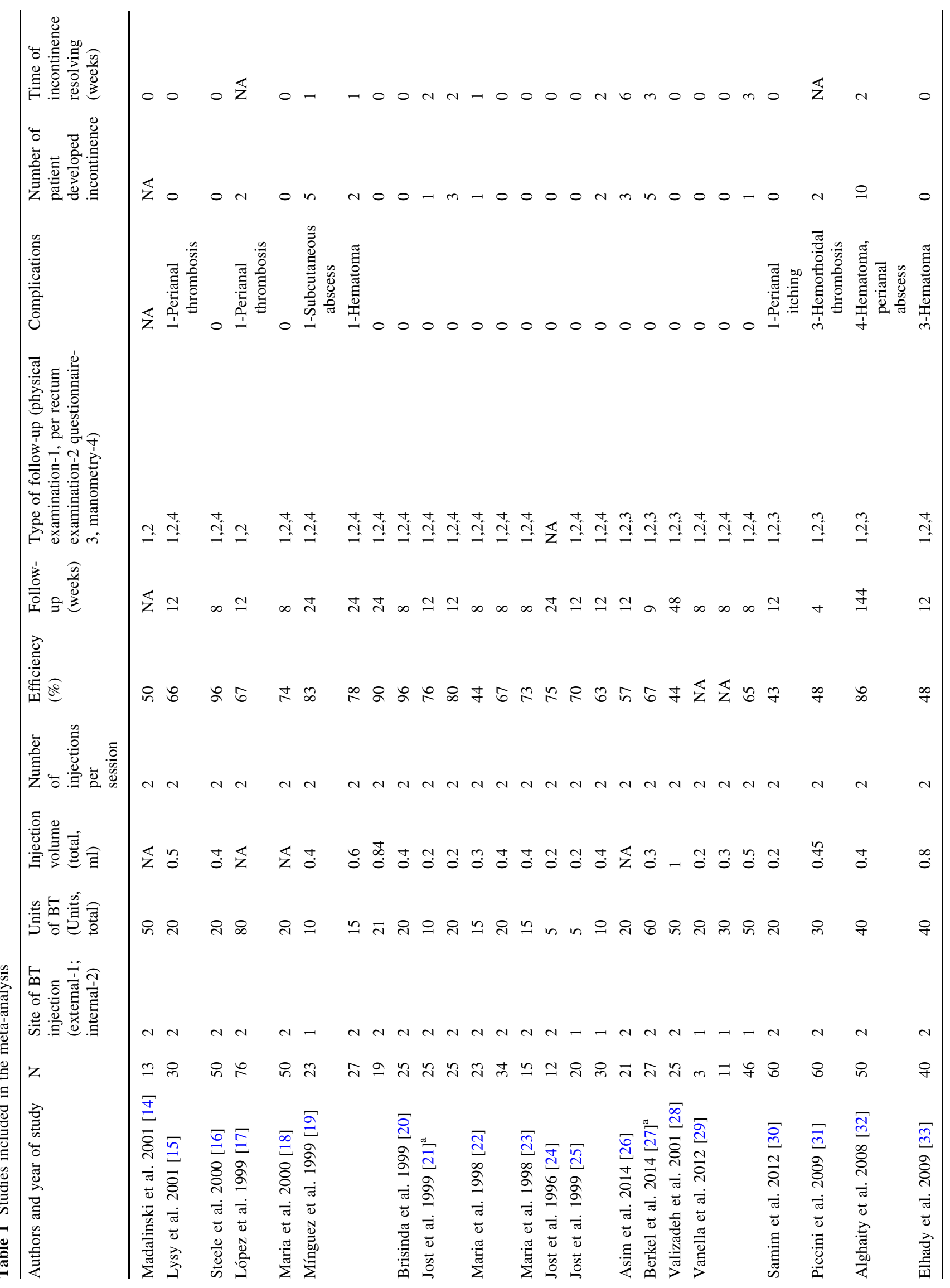




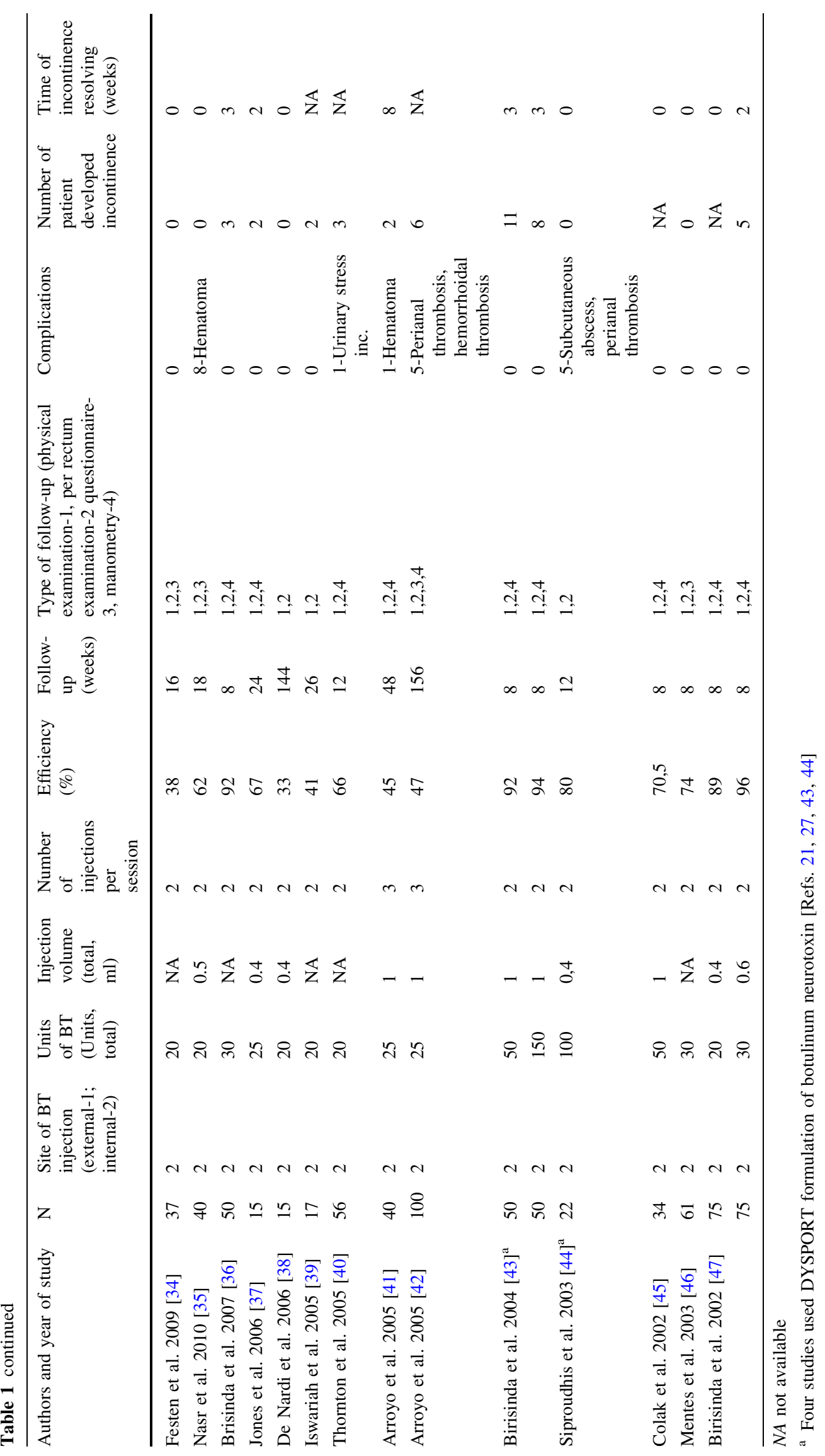




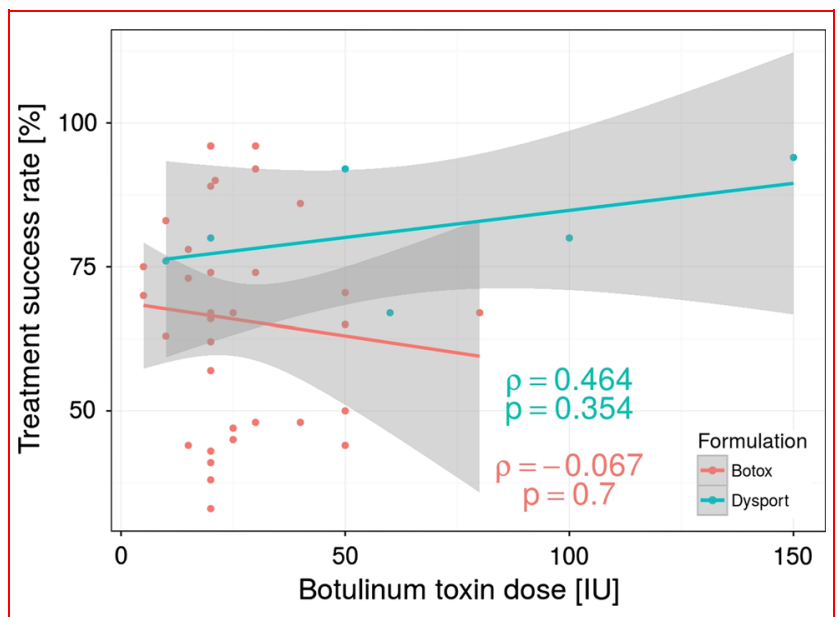

Fig. 2 Botulinum toxin injection dose used in the clinical studies in relation to the treatment success rate (defined as the percentage of positive treatment outcomes in all patients treated with BT) using two type of BT formulations (Botox and Dysport). Note the lack of dose dependency in positive therapy results. Each $d o t$ represents an independently treated patient group

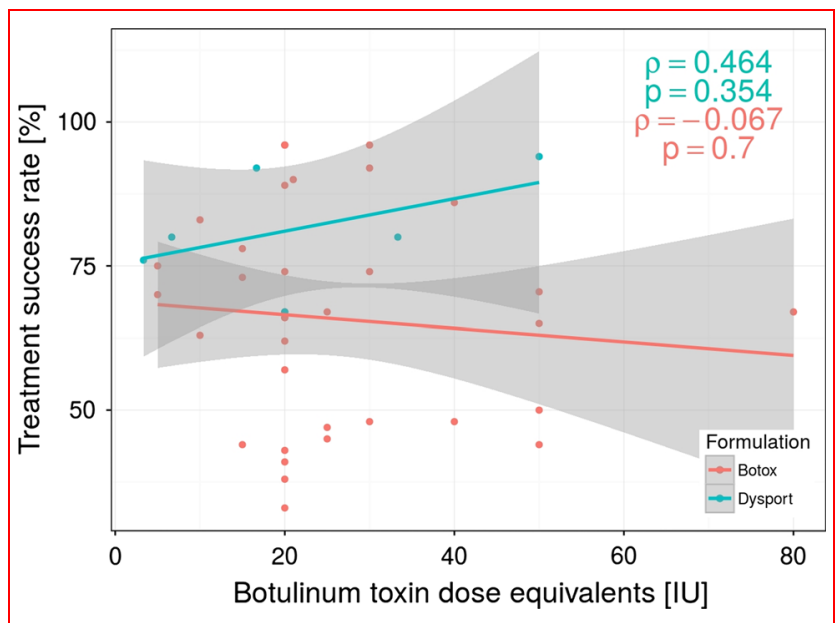

Fig. 3 Botulinum toxin injection dose used in the clinical studies in relation to the treatment success rate after conversion factor used (Dysport/Botox equivalency ratio of 3:1)

[43, 48-50]. However, based on these studies there are still some controversies regarding the optimal dosage of BT and its influence on efficiency of the CAF treatment. This metaanalysis showed that there is no dose-dependent efficiency of BT injection. Although the total number of injected units of BT ranged between 5 and 150 units per session, there was no statistical difference in the treatment success rate concerning the dosage of BT, for either Botox or Dysport formulations. However, some authors observed dose-dependent healing rates [19, 47]. Vinella et al. [29] reported no significant effect of different BT doses $(20,30$ and

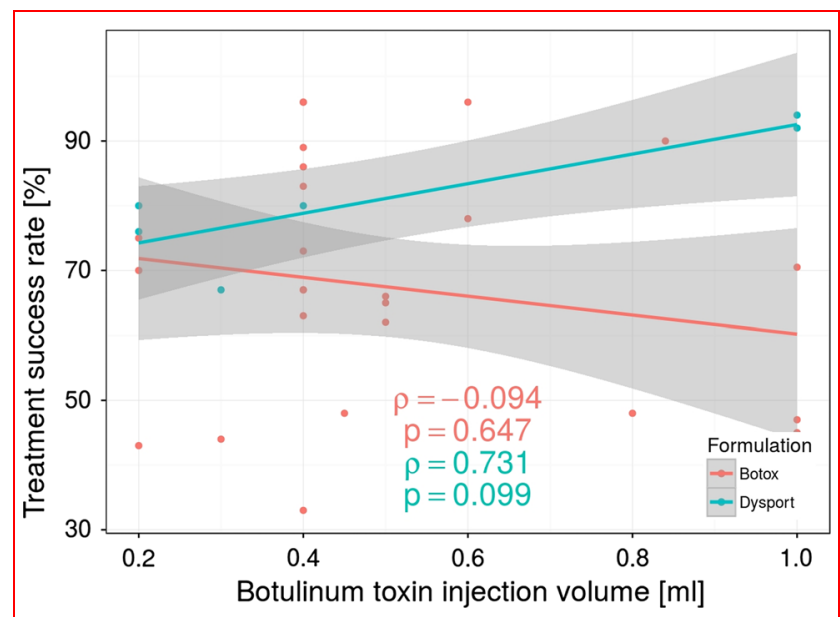

Fig. 4 Botulinum toxin injection volume used (Botox and Dysport formulations) in the clinical studies in relation to the treatment success rate. Note the lack of correlation positive therapy results. Each dot represents a group of patients treated with the same volume of the botulinum toxin but does not imply separate studies

$50 \mathrm{IU})$ and the site of injection on healing rate. Moreover, these results are in line with randomized controlled trial presented by Brisinda et al. [43] compared Botox versus Dysport formulations. Using a conversion factor of 1:3 for different BT formulations, there was no significance in healing rate. Based on current studies, the explanation of comparable results of CAF efficiency regardless the applied dosage of BT is unsolved. Some authors indicated diffusion of BT as an important factor which may boost the mechanism of action within target tissue [51-53]. Based on histologic staining of acetylcholinesterase, equal distribution of biological effect of BT was observed within the entire studied muscle when high dose of BT was applied, whereas in other experimental scenarios with low dose of BT injection, a gradient down the muscle was observed [51-53]. Diffusion of BT was also suggested as the most likely reason for no observable difference in healing rate using different BT dosages in CAF treatment [54]. Although some other factors such as presence of antibodies, cholinergic cells susceptibility to botulinum toxin or binding and/or internalizing properties of cholinergic cells have been proposed as a rationale explanation for varying clinical response to BT treatment, there is still no firm evidence support these hypothesis [43].

Only $2.2 \%$ of patients $(n=35)$ developed perianal complications due to BT injection based on presented meta-analysis. Thus, this result confirmed the advantage of BT injection regarding postoperative complications when compared to lateral internal sphincterotomy (LIS) [55]. Chen et al. [55] concluded that LIS is superior to BT for CAF considering healing rate and recurrence rate. However, BT injection was recommended for patients who 


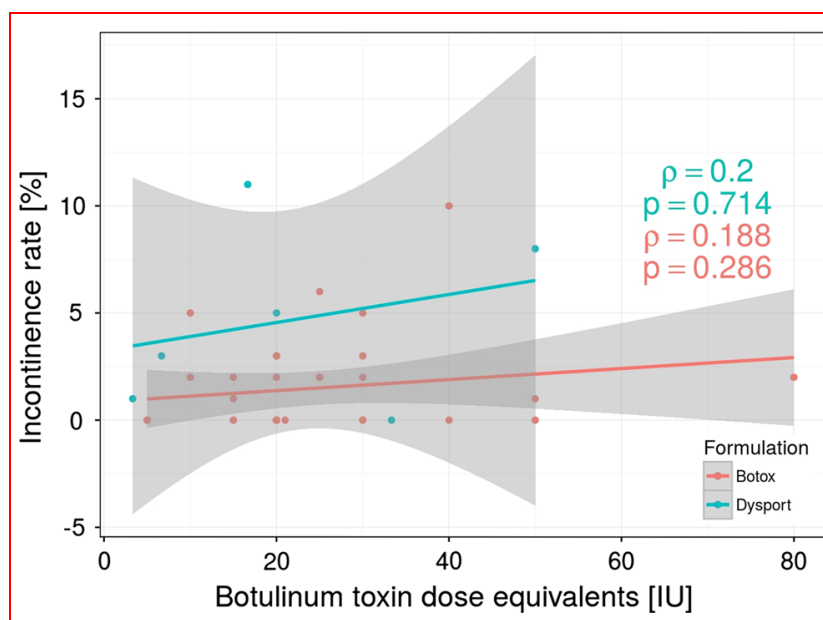

Fig. 6 Botox and Dysport (Dysport/Botox equivalency ratio of 3:1) dose injection does not correlate with the rate of postoperative fecal incontinence

either refuse surgical management, were previously treated with LIS or are at risk of developing postoperative incontinence (such as women with many vaginal deliveries, previous anal surgery or previously diagnosed incontinence). The overall incontinence rate based on this metaanalysis was established of $5.01 \%(n=79)$. Importantly, majority of patients reported only transient flatus or mucus incontinence that lasted up to 8 weeks postoperatively and disappeared spontaneously.

In majority of studies, only internal sphincter was injected. Explanation of such management is based on the underlying pathology of CAF associated with internal sphincter involvement. However, in some studies external sphincter muscle was preferably injected, supported by the

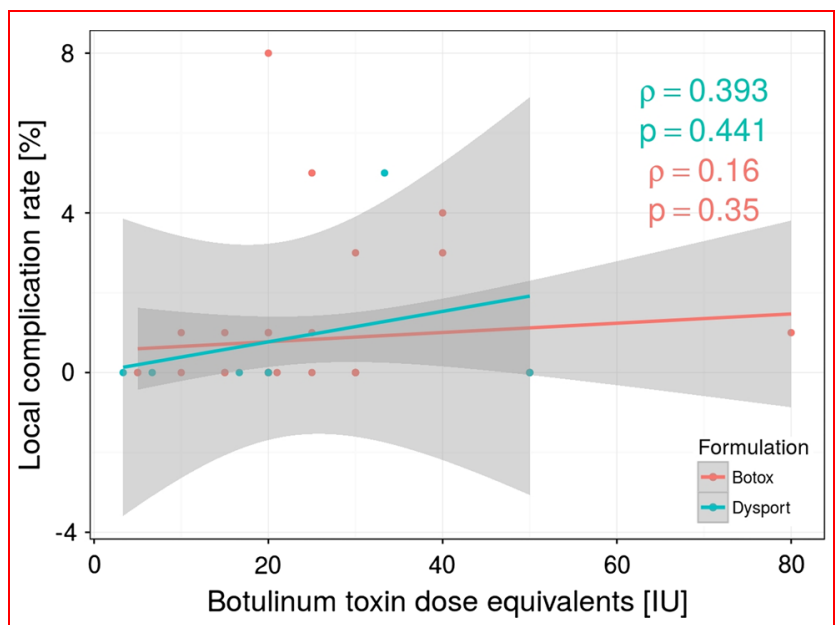

Fig. 5 Lack of correlation between the botulinum toxin doses related to the number of local postoperative complications regarding Botox and Dysport formulations used (Dysport/Botox equivalency ratio of $3: 1$ ) study indicating external anal sphincter muscle as a major contributor to the pathogenesis of CAF which seems to be precisely the opposite to other studies [21, 56]. Regardless of whether internal or external sphincters are injected, the results of healing rate are comparable. Possibly, BT diffuses into the internal anal following external sphincter injection and vice versa which was stated by Jost et al. $[21,56]$.

Recently, the attention has been paid to the psychological aspect in patients with CAF, resulting in varying responses to treatment. The high correlation with mental components was evidenced by significantly higher incidence of CAF in patients with type D (distressed) personality (defined as the co-occurrence of negative affect and social inhibition) [57]. While this type of personality generally represents $16 \%$ of the population, it raises up to $33 \%$ of in patients with CAF. In this group of patients, the symptoms associated with CAF are more easily recognized what may impair the quality of their life more than in patients with other type of personality [57]. It is also important to note that the placebo effect in patients treated for CAF is relatively high. Berry et al. [58] conducted placebo-controlled study comparing nitroglycerin (NTG) $0.4 \%$ ointment with placebo in patients with CAF. Surprisingly, the reduction in pain (defined as at least $50 \%$ due to visual analog scale, VAS) was achieved by $72.4 \%$ in the NTG group compared to $64.5 \%$ in the placebo group. Moreover, side effects (including headaches) were reported by $69.9 \%$ of patients treated with nitroglycerin ointment but also by $47.6 \%$ patients in the placebo group. The use of BT injection for CAF as a generally recommended and efficient method of treatment is per se the important aspect of management in this group of patients, which may also explain the no dose-dependent efficiency of BT.

Although the underlying pathology of achalasia, the course of the disease and the response for BT treatment is quite different, there is also no observed dose-dependent efficiency. Based on a recent large multicenter study, the administration of $100 \mathrm{IU}$ of BT (repeated 1 month later) was more efficacious than either 50 or 200 IU [59]. The same conclusion was achieved by Cuillière et al. [60]. An increased dose of BT from 100 to 200 IU did not significantly increase the success rate.

To limit the publication bias, the appropriate selection of studies was performed. However, this meta-analysis has some limitations. First, the time of outcome evaluation ranged from 4 to 156 weeks after BT injection which may possibly influence the efficiency rate. The use of BT might hasten the treatment of anal fissures. However, we did not confirm any significant correlation between the time period of BT injection and its efficiency. Second, although detailed selection of studies was performed, heterogeneity 
among analyzed studies exists due to a surgeon's preference and experience as well as the heterogenic sample of patients included into the study. Third, methodology of outcome evaluation differs among studies which may influence the interpretation of the results. Although in all studies clinical examination was performed, questionnaire and anorectal methodology were performed in ten and nineteen studies, respectively. Fourth, most studies were designed not as double-blinded studies which may also impact the outcomes.

\section{Conclusions}

Based on the present meta-analysis there is no BT dosedependent efficiency for CAF. Moreover, postoperative incontinence rate as well as complication rate is not related to the BT dosage. There was also no difference in healing rate observed in regard to the injection site and the number of injections per session. Further studies are needed in order to evaluate the real value and optimal dose of BT for CAF management. Moreover, the firm and unequivocal criteria for the definition of $\mathrm{CAF}$, end points and the evaluation of outcomes are needed in order to establish the optimal dose of BT injection for CAF treatment.

\section{Compliance with ethical standards}

Conflict of interest The authors declare that they have no conflict of interest.

Open Access This article is distributed under the terms of the Creative Commons Attribution 4.0 International License (http://crea tivecommons.org/licenses/by/4.0/), which permits unrestricted use, distribution, and reproduction in any medium, provided you give appropriate credit to the original author(s) and the source, provide a link to the Creative Commons license, and indicate if changes were made.

\section{References}

1. Lund JN, Scholefield JH (1996) Aetiology and treatment of anal fissure. Br J Surg 83:1335-1344

2. Schouten WR, Briel JW, Auwerda JJA et al (1996) Ischaemic nature of anal fissure. Br J Surg 83:63-65

3. Witte ME, Klaase JM (2007) Botulinum toxin A injection in ISDN ointment-resistant chronic anal fissures. Dig Surg 24:197-201

4. Schouten WR, Briel JW, Auwerda JJ (1994) Relationship between anal pressure and anodermal blood flow. The vascular pathogenesis of anal fissures. Dis Colon Rectum 37:664-669

5. Garcia-Aguilar J, Belmonte Montes C, Perez JJ et al (1998) Incontinence after lateral internal sphincterotomy: anatomical and functional evaluation. Dis Colon Rectum 41:423-427

6. Hsu TC, MacKeigan JM (1984) Surgical treatment of chronic anal fissure: a retrospective study of 1753 cases. Dis Colon Rectum 27:475-478
7. Songun I, Boutkan H, Delemarre JB et al (2003) Effect of isosorbide dinitrate ointment on anal fissure. Dig Surg 20:122-126

8. Dorfman G, Levitt M, Platell C (1992) Treatment of chronic anal fissure with topical glyceryl trinitrate. Dis Colon Rectum 42:1007-1010

9. Carapeti EA, Kamm MA, Phillips RK (2000) Topical diltiazem and bethanecol decrease anal sphincter pressure and heal anal fissures without side effects. Dis Colon Rectum 43:1359-1362

10. Richard CS, Gregoire R, Plewes EA et al (2000) Internal sphincterotomy is superior to topical nitroglycerin in the treatment of chronic anal fissure: results of a randomized, controlled trial by the Canadian Colorectal Surgical Trials Group. Dis Colon Rectum 43:1048-1057

11. Jonas M, Neal KR, Abercrombie JF et al (2001) A randomized trial of oral vs. topical diltiazem for chronic anal fissures. Dis Colon Rectum 44:1074-1078

12. Jankovic J, Brin MF (1991) Therapeutic uses of botulinum toxin. N Engl J Med 324:1186-1194

13. Jones OM, Moore JA, Brading AF et al (2003) Botulinum toxin injection inhibits myogenic tone and sympathetic nerve function in the porcine internal anal sphincter. Colorectal Dis 5:552-557

14. Madalinski MH, Slawek J, Zbytek B et al (2001) Topical nitrates and the higher doses of botulinum toxin for chronic anal fissure. Hepatogastroenterology 48(40):977-979

15. Lysy J, Israelit-Yatzkan Y, Sestiery-Ittah M et al (2001) Topical nitrates potentiate the effect of botulinum toxin in the treatment of patients with refractory anal fissure. Gut 48(2):221-224

16. Steele LS, Glazier R (2000) Are non-surgical treatments for anal fissure effective? Can Fam Phys 46:1063-1065

17. Fernández López F, Conde Freire R, Rios Rios A et al (1999) Botulinum toxin for the treatment of anal fissure. Dig Surg 16(6):515-518

18. Maria G, Brisinda G, Bentivoglio AR et al (2000) Influence of botulinum toxin site of injections on healing rate in patients with chronic anal fissure. Am J Surg 179(1):46-50

19. Mínguez M, Melo F, Espí A et al (1999) Therapeutic effects of different doses of botulinum toxin in chronic anal fissure. Dis Colon Rectum 42(8):1016-1021

20. Brisinda G, Maria G, Bentivoglio AR et al (1999) A comparison of injections of botulinum toxin and topical nitroglycerin ointment for the treatment of chronic anal fissure. N Engl J Med 341(2):65-69

21. Jost WH, Schrank B (1999) Chronic anal fissures treated with botulinum toxin injections: a dose-finding study with Dysport $\left({ }^{\circledR}\right)$. Colorectal Dis 1(1):26-28

22. Maria G, Brisinda G, Bentivoglio AR et al (1998) Botulinum toxin injections in the internal anal sphincter for the treatment of chronic anal fissure: long-term results after two different dosage regimens. Ann Surg 228(5):664-669

23. Maria G, Cassetta E, Gui D et al (1998) A comparison of botulinum toxin and saline for the treatment of chronic anal fissure. N Engl J Med 338(4):217-220

24. Jost WH, Schimrigk K (1994) Therapy of anal fissure using botulin toxin. Dis Colon Rectum 37(12):1340

25. Jost WH, Schrank B (1999) Repeat botulin toxin injections in anal fissure: in patients with relapse and after insufficient effect of first treatment. Dig Dis Sci 44(8):1588-1589

26. Asim M, Lowrie N, Stewart J et al (2014) Botulinum toxin versus botulinum toxin with low-dose glyceryl trinitrate for healing of chronic anal fissure: a prospective, randomised trial. $\mathrm{N} \mathrm{Z} \mathrm{Med} \mathrm{J}$ 127(1393):80-86

27. Berkel AE, Rosman C, Koop R et al (2014) Isosorbide dinitrate ointment vs botulinum toxin A (Dysport) as the primary treatment for chronic anal fissure: a randomized multicentre study. Colorectal Dis 16(10):360-366 
28. Valizadeh N, Jalaly NY, Hassanzadeh M et al (2012) Botulinum toxin injection versus lateral internal sphincterotomy for the treatment of chronic anal fissure: randomized prospective controlled trial. Langenbecks Arch Surg 397(7):1093-1098

29. Vanella S, Brisinda G, Marniga G et al (2012) Botulinum toxin for chronic anal fissure after biliopancreatic diversion for morbid obesity. World J Gastroenterol 18(10):1021-1027

30. Samim M, Twigt B, Stoker L et al (2012) Topical diltiazem cream versus botulinum toxin a for the treatment of chronic anal fissure: a double-blind randomized clinical trial. Ann Surg 255(1):18-22

31. Piccinni G, Poli E, Angrisano A et al (2009) Botox for chronic anal fissure: is it useful? A clinical experience with mid-term follow-up. Acta Biomed 80(3):238-242

32. Algaithy ZK (2008) Botulinum toxin versus surgical sphincterotomy in females with chronic anal fissure. Saudi Med J 29(9):1260-1263

33. Abd Elhady HM, Othman IH, Hablus MA et al (2009) Long-term prospective randomised clinical and manometric comparison between surgical and chemical sphincterotomy for treatment of chronic anal fissure. S Afr J Surg 47(4):112-114

34. Festen S, Gisbertz SS, van Schaagen F et al (2009) Blinded randomized clinical trial of botulinum toxin versus isosorbide dinitrate ointment for treatment of anal fissure. $\mathrm{Br} \mathrm{J}$ Surg 96(12):1393-1399

35. Nasr M, Ezzat H, Elsebae M (2010) Botulinum toxin injection versus lateral internal sphincterotomy in the treatment of chronic anal fissure: a randomized controlled trial. World J Surg 34(11):2730-2734

36. Brisinda GI, Cadeddu F, Brandara F et al (2007) Randomized clinical trial comparing botulinum toxin injections with $0.2 \%$ nitroglycerin ointment for chronic anal fissure. $\mathrm{Br} \mathrm{J}$ Surg 94(2):162-167

37. Jones OM, Ramalingam T, Merrie A et al (2006) Randomized clinical trial of botulinum toxin plus glyceryl trinitrate vs. botulinum toxin alone for medically resistant chronic anal fissure: overall poor healing rates. Dis Colon Rectum 49(10):1574-1580

38. De Nardi P, Ortolano E, Radaelli G et al (2006) Comparison of glycerine trinitrate and botulinum toxin-a for the treatment of chronic anal fissure: long-term results. Dis Colon Rectum 49(4):427-432

39. Iswariah H, Stephens J, Rieger $\mathrm{N}$ et al (2005) Randomized prospective controlled trial of lateral internal sphincterotomy versus injection of botulinum toxin for the treatment of idiopathic fissure in ano. ANZ J Surg 75(7):553-555

40. Thornton MJ, Kennedy ML, King DW (2005) Prospective manometric assessment of botulinum toxin and its correlation with healing of chronic anal fissure. Dis Colon Rectum 48(7):1424-1431

41. Arroyo A, Pérez F, Serrano P et al (2005) Surgical versus chemical (botulinum toxin) sphincterotomy for chronic anal fissure: long-term results of a prospective randomized clinical and manometric study. Am J Surg 189(4):429-434

42. Arroyo A, Perez F, Serrano P et al (2005) Long-term results of botulinum toxin for the treatment of chronic anal fissure: prospective clinical and manometric study. Int J Colorectal Dis 20(3):267-271

43. Brisinda G, Albanese A, Cadeddu F et al (2004) Botulinum neurotoxin to treat chronic anal fissure: results of a randomized
"Botox vs. Dysport" controlled trial. Aliment Pharmacol Ther 19(6):695-701

44. Siproudhis L, Sébille V, Pigot F et al (2003) Lack of efficacy of botulinum toxin in chronic anal fissure. Aliment Pharmacol Ther 18(5):515-524

45. Colak T, Ipek T, Kanik A et al (2002) A randomized trial of botulinum toxin vs lidocaine pomade for chronic anal fissure. Acta Gastroenterol Belg 65(4):187-190

46. Menteş BB, Irkörücü O, Akin M et al (2003) Comparison of botulinum toxin injection and lateral internal sphincterotomy for the treatment of chronic anal fissure. Dis Colon Rectum 46(2):232-237

47. Brisinda G, Maria G, Sganga G et al (2002) Effectiveness of higher doses of botulinum toxin to induce healing in patients with chronic anal fissures. Surgery 131(2):179-184

48. Jones OM, Brading AF, Mortensen NJ (2002) The mechanism of action of botulinum toxin on the internal anal sphincter. Colorect Dis 4(Suppl 1):71-72

49. Bhardwaj R, Drye E, Vaizey C (2006) Novel delivery of botulinum toxin for the treatment of anal fissures. Colorect Dis $8: 360-364$

50. Lindsey I, Cunningham C, Jones OM et al (2004) Fissurectomybotulinum toxin: a novel sphincter-sparing procedure for medically resistant chronic anal fissure. Dis Colon Rectum 47:1947-1952

51. Simpson LL (2000) Identification of the characteristics that underlie botulinum toxin potency: implications for designing novel drugs. Biochimie 82:943-953

52. Simpson LL, Maksymowych AB, Hao S (2001) The role of zinc binding in the biological activity of botulinum toxin. J Biol Chem 276:34-41

53. Pearce LB, Borodic GE, Johnson EA et al (1995) The median paralysis unit: a more pharmacologically relevant unit of biologic activity for botulinum toxin. Toxicon 33:217-227

54. Jost WH (1997) One hundred cases of anal fissure treated with botulin toxin; early and long-term results. Dis Colon Rectum 40:1029-1032

55. Chen HL, Woo XB, Wang HS et al (2014) Botulinum toxin injection versus lateral internal sphincterotomy for chronic anal fissure: a meta-analysis of randomized control trials. Tech Coloproctol 18(8):693-698

56. Jost WH, Mlitz H, Kaiser T et al (1997) The importance of sphincters in anal fissure. Int J Surg Sci 4:22-24

57. Sit M, Yilmaz EE, Canan F et al (2014) Health-related quality of life in patients with anal fissure: effect of type D personality. Prz Gastroenterol 9(2):93-98

58. Berry SM, Barish CF, Bhandari R et al (2013) Nitroglycerin $0.4 \%$ ointment vs placebo in the treatment of pain resulting from chronic anal fissure: a randomized, double-blind, placebo-controlled study. BMC Gastroenterol 13:106

59. Annese V, Bassotti G, Coccia G et al (2000) A multicentre randomised study of intrasphincteric botulinum toxin in patients with oesophageal achalasia. GISMAD Achalasia Study Group. Gut 46(5):597-600

60. Cuillière C, Ducrotté P, Zerbib F et al (1997) Achalasia: outcome of patients treated with intrasphincteric injection of botulinum toxin. Gut 41(1):87-92 